\title{
Entrevista Prof. Dr. Ricardo Zanetti Gomes: o papel das instituições de ensino superior no combate a Covid-19
}

\section{RESUMO}

Graziela Ferreira de Souza grazielasouza@alunos.utfpr.edu.br 0000-0001-5747-3210

Universidade Tecnológica Federal do Paraná; Universidade Estadual de Ponta Grossa, Ponta Grossa, Paraná, Brasil.

Sani de Carvalho Rutz da Silva sanirutz@utfpr.edu.br

0000-0002-1548-5739

Universidade Tecnológica Federal do Paraná, Ponta Grossa, Paraná, Brasil.

Nilcéia Aparecida Maciel Pinheiro nilceia@utfpr.edu.br

0000-0003-3313-1472

Universidade Tecnológica Federal do Paraná, Ponta Grossa, Paraná, Brasil.
A entrevista desta primeira edição de 2020 da Revista Brasileira de Ensino de Ciência e Tecnologia tem como objetivo dar luz a um momento histórico importante pelo qual nossa sociedade vem passando. A convite dos editores da RBECT o Prof. Dr. Ricardo Zanetti Gomes, coordenador do Curso de Medicina da Universidade Estadual de Ponta Grossa, apresenta ações e reflexões sobre os esforços cooperados entre profissionais da saúde, pesquisadores professores, acadêmicos e comunidade no combate a pandemia causada pelo Corona Vírus.

PALAVRAS-CHAVE: Covid-19. Ciência. Saúde. Pesquisa. Universidade Pública. 


\section{APRESENTAÇÃO}

Ricardo Zanetti Gomes é médico, professor e pesquisador da Área da Saúde. Possui mestrado e doutorado em Medicina (Clínica Cirúrgica) pela Universidade Federal do Paraná (UFPR) e é especialista em Cirurgia Vascular, Angiorradiologia e Cirurgia Endovascular, áreas em que atua com clínica médica.

É Professor Associado do Departamento de Medicina da Universidade Estadual de Ponta Grossa(UEPG), onde atualmente também exerce função de Representante Docente junto ao Conselho de Administração.

Possui ampla experiência na atuação clínica e desde 2018 está à frente da Coordenação do Curso de Medicina da UEPG. Dedica-se a projetos de pesquisa que envolvem a graduação, sobretudo a extensão em ações ligadas ao atendimento à comunidade.

Nessa perspectiva, o convidado para a entrevista da primeira edição de 2020 da Revista Brasileira de Ciência e Tecnologia nos apresenta um panorama das ações desenvolvidas pelo Curso de Medicina no combate a pandemia causada pelo novo corona vírus e traça um importante panorama sobre o papel das instituições de ensino superior no enfrentamento a esta doença.

Prof. Dr. Ricardo Zanetti Gomes

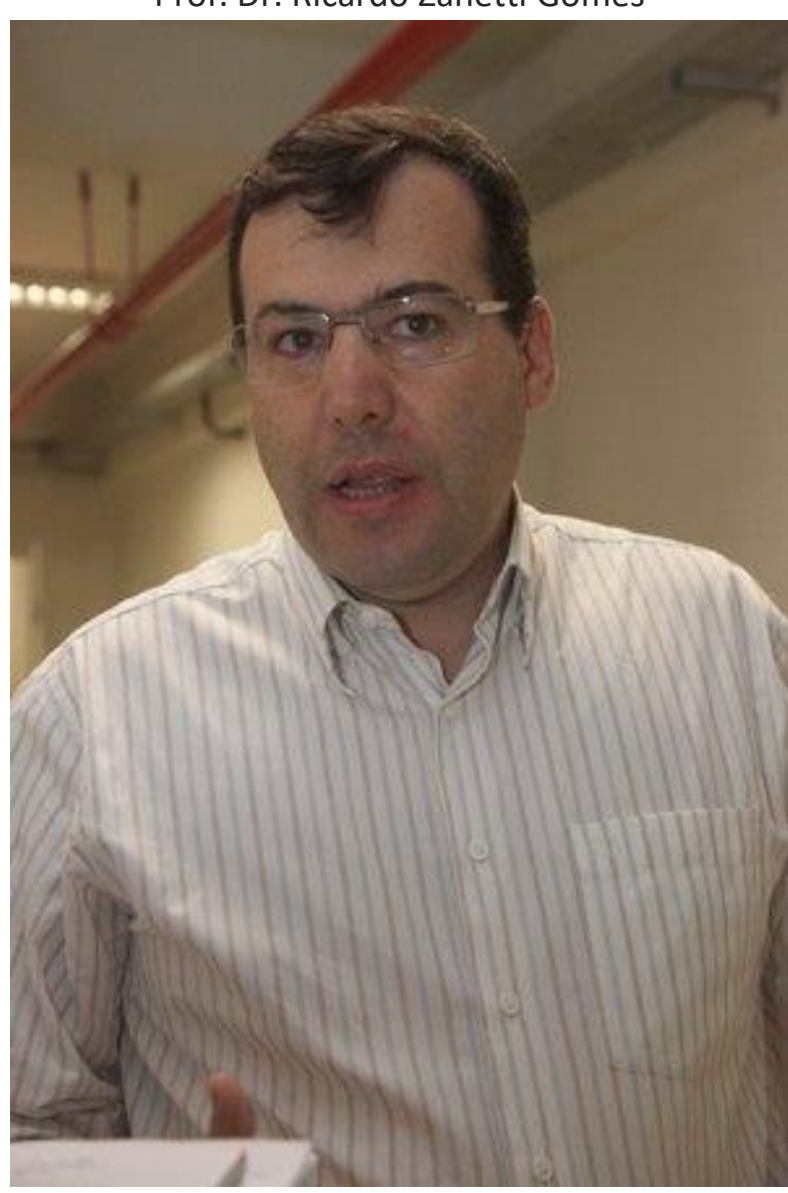

Fonte: Acervo pessoal. 


\section{ENTREVISTA}

Atualmente o senhor está a frente da coordenação do Curso de Medicina da Universidade Estadual de Ponta Grossa. Como o curso, seus acadêmicos e professores vêm se mobilizando para atuar no combate a pandemia da COVID19 ?

Sim, estou como coordenador do Curso da Medicina da UEPG, e neste momento, a universidade está com o calendário suspenso, logo, sem aulas. Mesmo os estágios nos hospitais e unidades básicas de saúde estão parados. Nesse sentido, estamos atuando por meio de duas atividades extensionistas: uma junto a Fundação Araucária no enfrentamento à COVID-19 e outra atividade é o "UEPG Abraça", a qual se ampliou para abraçar toda a comunidade dos Campos Gerais, com apoio psicológico e emocional para a população que se encontra em isolamento social.

Mesmo diante de inúmeros cortes nos recursos humanos e materiais das instituições públicas de ensino superior vemos hoje uma grande corrida das universidades no contingenciamento da COVID-19 com a produção de equipamentos e suprimentos para as equipes de saúde. Vemos também, o avanço de pesquisas para combate a pandemia. $O$ que podemos destacar das ações do curso de medicina da Universidade Estadual de Ponta Grossa e seus parceiros institucionais?

A UEPG, junto a todos os cursos da área da saúde, entre eles o de Medicina, tem agido junto as atividades extensionista, atendendo via call center da UEPG ou pela plataforma COVID19 Paraná', app desenvolvido pelo CELEPAR. Seu objetivo é esclarecer a população quanto ao diagnóstico e estratificação de risco, de maneira a orientar orientando a população nos cuidados de prevenção, bem como nos casos de sintomas gripais, orientando o fluxo destes pacientes para as Unidades Básicas de Saúde (UBS), Unidades de Pronto Atendimento (UPA) (dependendo da gravidade) ou ainda encaminhando para consultas médicas por TELEMEDICINA, o que é um novo paradigma na área da saúde.

Considera que o apoio dessas instituições de ensino superior (IES), poderá trazer benefícios no enfrentamento à COVID-19 no cenário brasileiro?

As IES existem para servir a comunidade, através por meio da graduação onde há a formação de profissionais competentes. Esses profissionais, desenvolvem pesquisas, nas quais novos horizontes se descortinam com soluções inovadoras, nos mais diversos campos, como é o caso das engenharias, por meio de profissionais treinados para resolver problemas. Mas vale lembrar que todas as áreas da ciência geram novos conhecimentos, como por exemplos as Ciências Sociais Aplicadas resolvendo problemas econômicos. Além disso, enfatizo o terceiro elemento que sustenta as IES que é a extensão, ou seja, prestação de serviço à comunidade, no qual as universidades com seus alunos, servidores, pesquisadores, professores se mobilizam para cuidar da sociedade com serviço eficiente e de qualidade. 
Ao mesmo tempo em que percebemos respostas e avanços dados pela comunidade científica às necessidades da sociedade, constata-se que o movimento de negação e refutação da ciência é algo presente nas discussões da sociedade. Considera que os esforços cooperados das instituições públicas de ensino em busca de soluções, suprimentos e avanços tecnológicos podem ser considerados como fatores de fortalecimento da ciência e uma resposta às críticas aos pesquisadores brasileiros?

Esta foi a pergunta mais desafiadora até agora, existe, e isto é inegável, um distanciamento entre a academia e a sociedade como um todo, e penso que é hora das universidades abrirem seus portões para a comunidade e nortear as pesquisas para as necessidades da população. Devemos ouvir o que a sociedade, seus problemas e aí desenvolvermos a solução. Crise é momento de oportunidade, então é a hora da academia aproximar-se da comunidade oferecendo profissionais competentes, pesquisas que solucionem os problemas da sociedade brasileira e extensão com prestação de serviço.

Quanto ao processo de negação citado na pergunta, ele é a primeira fase para a solução do problema, depois haverá a fase da barganha e outras, até chegamos a aceitação, ou seja, o caminho será longo, mas repito, crise também é oportunidade.

Já é possível pensar em um cenário pós-pandemia e suas implicações na formação acadêmica e nas pesquisas na área da saúde?

O cenário pós-pandemia será de intensa recessão econômica, e a pesquisa, também enfrentará cortes, assim como o cenário que os formandos e egressos enfrentarão será muito difícil. Teremos poucos empregos, porém, com a retomada do crescimento econômico, novas oportunidades aparecerão e teremos um novo mundo e um novo Brasil, mais forte e melhor preparado para enfrentar novos desafios.

Que mensagem deixaria aos pesquisadores das mais diversas áreas da ciência que nos leem por meio da Revista Brasileira de Ensino de Ciência e Tecnologia?

Em um momento de crise, novas oportunidades se descortinarão e para enxergarmos precisaremos de flexibilidade e grande capacidade de adaptação às novidades deste novo mundo pós-pandemia. 
1 O "COVID19 Paraná" é um aplicativos para aparelhos móveis desenvolvido pela CELEPAR, empresa estadual de tecnologia da informação, em parceria com a Secretaria da Saúde. A ferramenta tem como objetivos auxiliar na avaliação de sintomas da população local, coletando informações cadastrais para composição de um questionário epidemiológico auto aplicável, cujas respostas auxiliam na tomada de decisões no combate ao vírus.

\section{REFERÊNCIAS}

GOMES, Ricardo Zanetti. Currículo do sistema currículo Lattes. [Brasília], $31 \mathrm{mar}$ 2020. Disponível em: http://lattes.cnpq.br/8881832386198407 . Acesso em: 14 abr. 2020. 